\title{
Use of Blue and Blue-Violet Lasers in Dentistry: A Narrative Review
}

\author{
Carlo Fornaini ${ }^{1,2,3 *}$, Reza Fekrazad ${ }^{4,5}{ }^{\circledR}$, Jean-Paul Rocca ${ }^{1,3}{ }^{\circledR}$, Shiying Zhang $^{3}{ }^{\circledR}$, Elisabetta Merigo ${ }^{1,3}{ }^{\circledR}$ \\ 'Laboratoire MICORALIS (MICrobiologie ORALe, Immunothérapie et Santé) EA7354, Université Nice Sophia Antipolis, \\ UFR Odontologie, Avenue des Diables Bleus, 06000 Nice, France \\ ${ }^{2}$ Group of Applied Electro Magnetics (GAEM), Department of Engineering and Architecture, University of Parma, Viale G. P. \\ Usberti 181/A -43124 -Parma, Italy \\ ${ }^{3}$ 2nd Hospital Shijiazhuang, Dept. of Stomatology, 53 Huaxi Road, Shijiazhuang 050051, China \\ ${ }^{4}$ Radiation Sciences Research Center, Laser Research Center in Medical Sciences, AJA University of Medical Sciences, \\ Tehran, Iran \\ ${ }^{5}$ International Network for Photo Medicine and Photo Dynamic Therapy (INPMPDT), Universal Scientific Education and \\ Research Network (USERN), Tehran, Iran
}

\section{*Correspondence to \\ Carlo Fornaini, \\ Laboratoire MICORALIS \\ (MICrobiologie ORALe, \\ Immunothérapie et Santé) \\ EA7354, Université Nice Sophia Antipolis, \\ UFR Odontologie, Avenue des \\ Diables Bleus, 06000 Nice, \\ France \\ Email: carlo@fornainident.it}

Received: April 26, 2020 Accepted: December 6, 2020 epublished: July 4, 2021

\begin{abstract}
Introduction: Blue and blue-violet diode lasers (450 and $405 \mathrm{~nm}$ ) seem to represent an interesting approach for several clinical treatments today. The aim of this narrative review is to describe and comment on the literature regarding the utilization of blue and blue-violet lasers in dentistry. Methods: A search for "blue laser AND dentistry" was conducted using the PubMed database, and all the papers referring to this topic, ranging from 1990 to April 2020, were analyzed in the review. All the original in vivo and in vitro studies using $450 \mathrm{~nm}$ or $405 \mathrm{~nm}$ lasers were included in this study. All the articles on the LED light, laser wavelengths other than 405 and $450 \mathrm{~nm}$ and using lasers in specialties other than dentistry, as well as case reports, guideline papers and reviews were excluded. Results: From a total of 519 results, 47 articles met the inclusion criteria and were divided into 8 groups based on their fields of application: disinfection (10), photobiomodulation (PBM) (4), bleaching (1), resin curing (20), surgery (7), periodontics (1), endodontics (1) and orthodontics (3). Conclusion: Blue and blue-violet diode lasers may represent new and effective devices to be used in a large number of applications in dentistry, even if further studies will be necessary to fully clarify the potentialities of these laser wavelengths.

Keywords: Diode laser; Dentistry; Photobiomodulation; Oral surgery; Orthodontics.
\end{abstract}

\section{Introduction}

The first paper regarding the utilization of laser technology in dentistry was published in 1988 by John Frame, who described a surgical intervention in the mouth, performed with a $\mathrm{CO} 2$ laser. $^{1}$

Since then, so-called "laser-assisted dentistry" has increased its fields of application, and new

appliances have been introduced regularly with the aim of obtaining better results and because of the comfort it brings to patients.

One important step in this process was represented by the introduction in the dental market of diodelasers characterized by low size and cost, optic fiber delivery system and maintenance-free. ${ }^{2}$

The laser wavelengths used in dentistry have been limited to those located in the infrared portion of the electromagnetic spectrum. The first group in the near infrared due to the great absorption in haemoglobin (Nd:YAG, diodes) is mainly used in soft-tissue oral surgery; the second group is in thefar infrared and, thanks to its high affinity with water and hydroxyapatite (Er:YAG, Er,Cr:YSGG and CO2), it may also be used for bone surgery and conservative treatments. ${ }^{3}$

As proposed by some authors, ${ }^{4,5}$ the KTP and argon lasers are two exceptions: the former has a solid active medium emitting in the green spectrum $(532 \mathrm{~nm})$ and the latter has a gas active medium emitting in the blue spectrum (470 nm), but due to their high costs, they have not been really used indentistry.

The possibility of diode lasers wavelengths ranging from 405 to $2000 \mathrm{~nm}$ has added new possibilitiesfor dental treatments and consequently, several studies have been performed to determine the best choice for patients from the point of view of laser-tissue interactions.

An interesting ex vivo study with Sprague Dawley rats, based on the supercontinuum source, demonstrated that the best-absorbed wavelengths by different soft tissues are those around 400/500 $\mathrm{nm}$ (blue and green) and $1500 \mathrm{~nm}$ 
(middle infra-red), which are not often used in dentistry. ${ }^{6}$ On the basis of these considerations reported, blue lasers recently started to be utilized in dentistry; therefore, several studies appeared in the literature.

This narrative review aims to describe the use of blue and blue-violet lasers in dentistry, their advantages, disadvantages and indications, and to define what are the best parameters suggested by the literature.

\section{Materials and Methods}

A search for "blue laser AND dentistry" was performed using the PubMed database and all the papersreferring to this topic, ranging from 1990 to April 2020, were analyzed. The reference lists of all eligible articles were examined, and additional studies were added to the review only if they were indexed on PubMed. All the original in vivo and in vitro studies applying $450 \mathrm{~nm}$ or $405 \mathrm{~nm}$ lasers were included in this study. All the articles on the LED light, laser wavelengths other than 405 and $450 \mathrm{~nm}$, using lasers in specialties other than dentistry were excluded, as well as case reports, guidelines paper and reviews.

The inclusion criteria were as follows: (1) clinical trials which analyzed the effectiveness of 405 or $450 \mathrm{~nm}$ lasers without a control group or with a control (no treatment of any kind) and/or "traditional"treatment group; (2) studies wherein outcomes were clearly described; (3) studies published in English, French or Italian language.

After a discussion among reviewers (CF and EM) it was decided to include trials without control or placebo arms because of the limited number of publications on the chosen topic.

The exclusion criteria were as follows: (1) literature reviews, case or letter reports, and unpublished theses or congress presentation/posters; (2) studies that used LED or lasers other than 405 or $450 \mathrm{~nm}$;

(3) papers published in languages other than English, French or Italian.

A search of major dental laser journals was conducted. The references of all articles identified for thereview and other relevant reviews were also searched; any contrast was decided by a consultation with a third reviewer (JPR).

As suggested by Christenson in 2007 (evidence-based laboratory medicine - a guide for critical evaluation of in vitro laboratory testing), we used the CAPO question formulation $(\mathrm{CAPO}=\mathrm{C}$ for Case,A for Assay or Laboratory Procedure, $\mathrm{P}$ for Predicate or reference standard and $\mathrm{O}$ for Outcome).

The methodological quality of the included studies was realized using Cochrane's collaboration tool analyzing selection bias (adequate random sequence generation - adequate allocation concealment), performance bias (adequate participant blinding - adequate personnel blinding), attrition bias (acceptable and described dropout rate), reporting bias (no selective outcome reporting) and detectionbias (adequate outcome assessor blinding).

A meta-analysis was performed with Review Manager software (5.0.16 Version).

\section{Results}

From a total of 519 results, 47 articles met the inclusion criteria and were divided into 8 groups based on their fields of application: disinfection, photobiomodulation (PBM), bleaching, resin curing, surgery, periodontics, endodontics and orthodontics. Results are shown in Table 1.

\section{Discussion}

\section{Tissue Decontamination}

The first studies regarding $405 \mathrm{~nm}$ lasers investigated their

Table 1. Results of the Study

\begin{tabular}{lc}
\hline Studies & Number \\
\hline Total of the studies found & 519 \\
Excluded & 472 \\
Tissue decontamination & 10 \\
Photobiomodulation & 4 \\
Bleaching & 1 \\
Composite photopolymerization & 20 \\
Oral surgery & 7 \\
Periodontics & 1 \\
Endodontics & 1 \\
Orthodontics & 3 \\
\hline
\end{tabular}

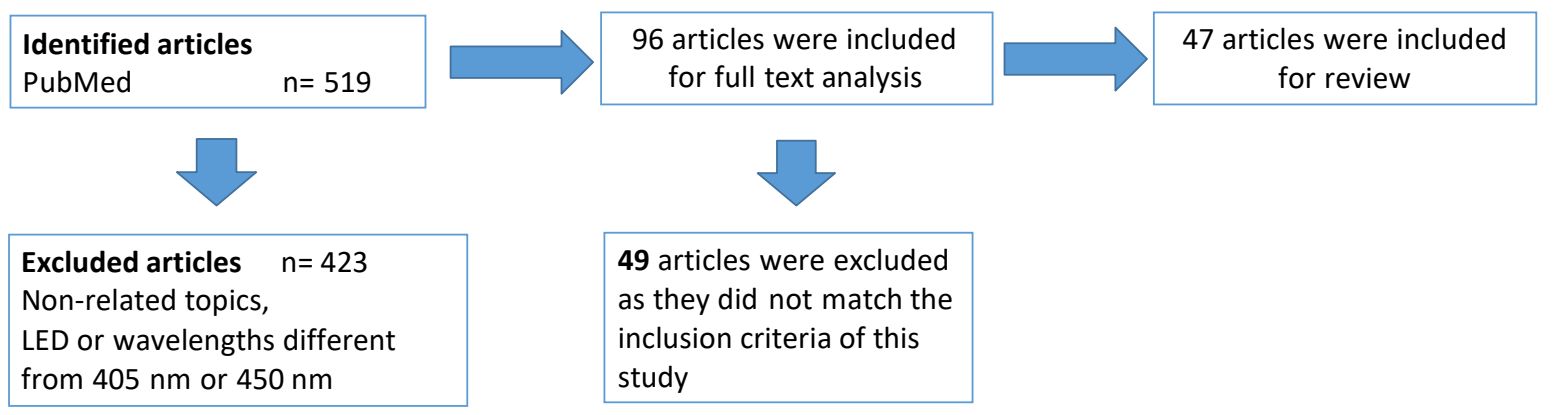

Figure 1. Flow Chart of the Research Method 
antibacterial power, particularly against bacteria which are normally present in the mouth and responsible for a large number of oral diseases. Through several in vitro studies, Masson-Meyers et al have been very active in investigating the role of blue lasers against Staphylococcus aureus and Escherichia coli, even when they are resistant to antibiotics. ${ }^{7}$ Due to the successful results obtained at $40 / 121 \mathrm{~J} / \mathrm{cm}^{2}$, the authors defined blue light as "an emerging alternative to antibiotics"s. The same authors demonstrated that the mechanism of this antimicrobic effect consists of the alteration of the membrane integrity, with a consequent decrease in membrane polarization and a rapid alteration of vital cellular functions. ${ }^{9}$

These results were also confirmed by de Sousa et al, who irradiated strains of Staphylococcus aureus ATCC 25923, Pseudomonas aeruginosa ATCC 27853, and Escherichia coli ATCC 25922 with a blue laser $(450 \mathrm{~nm})$ with energy densities of 0 (control), 3, 6, 12, 18, and $24 \mathrm{~J} / \mathrm{cm}^{2}$. Fluences lower than $6 \mathrm{~J} / \mathrm{cm}^{2}$ showed the inhibition of the growth of $S$. aureus and $P$. aeruginosa and all tested fluencesexcept at $24 \mathrm{~J} / \mathrm{cm}^{2}$, showed the inhibition of E. coli. ${ }^{10}$

Due to the importance of photodynamic therapy in the decontamination of the oral cavity, demonstrated many years ago, Merigo et al, in several studies, compared the behaviour of three laser

wavelengths, blue $(405 \mathrm{~nm})$, green $(532 \mathrm{~nm})$ and red $(650 \mathrm{~nm})$, coupled with three different chromophores (toluidine blue, erythrosine and curcumin).

In the first study, ${ }^{11}$ the lasers were used on Candida albicans cultures and in a model of Galleria mellonella infected by Candida albicans. The three different wavelengths (532, 405 and $650 \mathrm{~nm}$ ) were used in $\mathrm{CW}$ at three different energy densities $\left(10,20\right.$ and $\left.30 \mathrm{~J} / \mathrm{cm}^{2}\right)$ with and without chromophore.

The cells irradiated without chromophore did not show growth inhibition and the best result $(100 \%$ of growth inhibition) was reached with $405 \mathrm{~nm}$ diode laser irradiation coupled with curcumin at all the used fluences. The survival of $G$. mellonella larvae infected with C. albicans after laser application with or without dyes showed a statistically significant difference $(P<0.001)$ in comparison with the proper control groups.

The same authors performed another in vitro study ${ }^{12}$ in which laser irradiation was used on Streptococcus mutans with the same wavelengths, photosensitizers and parameters. The inhibition of the growth was not shown using the red diode at any fluence value while it was obtained using the blue diode and green lasers and inhibition rates of $40.7 \%$ and $40.2 \%$ were reached; the best results were obtained with the blue diode laser and curcumin (growth inhibition up to $99.26 \%$ at $30 \mathrm{~J} / \mathrm{cm}^{2}$ fluence).

In a third study, ${ }^{13}$ the authors studied the effects of the same wavelengths, agents and parameters on a biofilm of C. albicans with or without a KP (synthetic killer decapeptide). They concluded that a treatment with a blue laser, curcumin and KP, as well as a green laser, erythrosine and KP, led to the death of most C. albicans cells. Furthermore, KP alone reduced biofilm viability, but it was notable to cause C. albicans death.

These results were also confirmed by the study of Azizi et al, ${ }^{14}$ who demonstrated that the irradiation with a 460 $\mathrm{nm}$ laser coupled with curcumin at continuous wave (CW) and low energy had a significant effect on the growth inhibition of S. mutans bacterial colonies, showing significant differences when compared toa $660 \mathrm{~nm}$ laser with methylene blue as well as the photosensitizer alone.

In a recent in vitro and in vivo study, Rupel et a ${ }^{15}$ demonstrated the capacity of the blue laser $(450 \mathrm{~nm})$ to inhibit the biofilm formation due to the strong action of oxidative stress inhibition; The authors eradicated $P$. aeruginosa cells, grown in the planktonic state, agar plates and mature biofilms with minimal toxicity to mammalian cells and tissues. This result was confirmed in a mouse model of skin wound infection, introducing this kind of phototherapy as an innovative approach to inhibit bacterial growth and biofilm formation, and a realistic treatment option for superinfected wounds.

The effect of laser irradiation on viruses is an aspect which has barely been investigated, and the literature about it is very poor; Zupin et al realized an experimental model of Herpes simplex type 1

virus (HSV-1) infection and demonstrated a direct inhibitory effect with $445 \mathrm{~nm}$ laser irradiation evenat low power density $\left(0.15-0.30 \mathrm{~W} / \mathrm{cm}^{2}\right) .{ }^{16}$

\section{Photobiomodulation}

$\mathrm{PBM}$ is the universally recognized term to define the wide range of laser applications with low parameters and has finally taken the place of a large number of definitions such as "Low-level laser therapy", "biostimulation", "soft laser" or "cold laser". Mostly used in the 1970s and 1980s, this term was added as a MeSH term in the National Library of Medicine's controlled vocabulary thesaurus in 2015. ${ }^{17}$ The most important effects of PBM, from a clinical point of view, may be found in the stimulation and acceleration of the healing process, the anti-inflammatory effect, and thepainkilling action, ${ }^{18}$ and today it is universally accepted that all laser and LED wavelengths-blue included-are able, when emitted with proper parameters, to produce PBM.

Kushibiki and Awazu demonstrated that the $405 \mathrm{~nm}$ laser irradiation of mesenchymal stem cells (MSCs) can lead to the osteogenesis and adipogenesis of mouse MSCs by altering the intracellular localization of the circadian rhythm protein cryptochrome 1 (mCRY1), promoting osteogenesis and reducing the adipogenesis of MSCs, inducing the translocation of mCRY1 and mammalian period circadian clock 2 (mPER2) from the cytoplasm to the nucleus, and decreasing mCRY1 mRNA levels as 
quantified by real-time polymerase chain reaction. ${ }^{19,20}$

In a different study, Kushibiki et $\mathrm{al}^{21}$ also demonstrated an increase in the intracellular reactive oxygen species (ROS), which are considered to be the key secondary messengers produced by PBMafter blue laser irradiation, in various types of cells, including mouse preadipocytes (3T3-L1), prechondrocytes (ATDC5), myoblasts (C2C12), mesenchymal stromal cells (KUSA-A1), lung cancer cells (LLC), insulinoma cells (MIN6), fibroblasts (NIH-3T3), human cervix adenocarcinomacells (HeLa), and macrophages differentiated from lymphocytes (THP-1), after treatment with phorbol ester and rat basophilic leukemia cells (RBL-2H3).

The most interesting aspect of this study may be the observation that intracellular ROS generation was not observed after irradiation with a red laser or near-infrared laser.

Mikami et al, by irradiating the MC3T3-E1 osteoblast cell line with a $405 \mathrm{~nm}$ laser at low-level ultra-high frequency (UHF) and ultrashort pulses (USP), described significantly enhanced cell proliferation and alkaline phosphatase (ALP) activity, compared with both the non-irradiated control and PBM using a continuous-wave mode, without significant elevation of temperature. Furthermore, osterix (Osx) and ALP mRNAs significantly increased compared to those of the control on days 3 and 7 following PBM at $5.6 \mathrm{~J} / \mathrm{cm}^{2}$, suggesting that a $405 \mathrm{~nm}$ UHF-USP blue laser enhances the extracellular calcification of osteoblasts by upregulating proliferation and differentiation. ${ }^{22}$

\section{Laser-Assisted Dental Bleaching}

The possibility of eliminating teeth discoloration by applying hydrogen peroxide (HP) was describedby Fisher in $1911^{23}$ and subsequently, many tools have been proposed to improve the effect of HP, including laser irradiation. Even if most authors described the role of lasers in dental bleaching as limited to a thermal effect which is able to catalyze the reaction of HP dissociation into water and oxygen, Fornaini et al, by comparing KTP and $808 \mathrm{~nm}$ diode lasers, demonstrated that this was not true and proposed different mechanisms in which the production of free radicals was involved, considering the visible laser wavelengths to be the most effective and active. ${ }^{24}$

There are not many studies on the use of blue lasers in dental bleaching, even if the argon laser has been cleared by the FDA as one of the three dental laser wavelengths for tooth whitening. ${ }^{25}$ Tano et al, in an in vitro study, considered the $405 \mathrm{~nm}$ diode laser to be very efficient even at a low concentration of HP; in fact, good results were reached with $3.5 \% \mathrm{H}_{2} \mathrm{O}_{2}$ coupled with $\mathrm{VL}-\mathrm{TiO} 2$ as anadjuvant. $^{26}$

\section{Composite Resin Photopolymerization}

The literature describing the advantages of blue laser irradiation for composite resin polymerization was very rich in the period 1980-1990, when argon lasers were used in dentistry, due to their wavelength of 468 $\mathrm{nm}$ representing the maximum of the camphorquinone absorption coefficient. ${ }^{27}$ Benedicenti et al, in several studies in which argon lasers were compared to UV and halogen light, showed the immediate advantages and long-term clinical aspects ${ }^{28-32}$ of an argon laser, analyzed the water absorption and the hardness of the composite, and evaluated its wear as well.

Séverin proposed the utilization of an Argon laser for orthodontic brackets bonding. ${ }^{33}$

Powell et al. demonstrated that an argon laser enhances the physical properties of some composite resins, such as flexural modulus, diametral tensile and transverse flexural strengths, with irradiation times lower than these used with conventional sources ${ }^{34-37}$ and proposed the proper parameters of argon laser irradiation. ${ }^{38}$

Calura et al underlined the shortest irradiation time of lasers when compared to halogen lamps ${ }^{39}$ while Shanthala and Munshi, in an in vitro study on primary teeth, showed with a 10-second laser exposure, a shear bond strength higher than the one obtained with a halogen lamp polymerization with a 40 - second exposure, ${ }^{40}$ and these data were also confirmed by the study of Fleming and Maillet. ${ }^{41}$

Pahlevan et $\mathrm{al}^{42}$ measured the degree of conversion (DC) using Fourier-transform infrared spectroscopy and showed that the argon laser gave the lowest temperature rise, even if the DC obtained by the different curing units was not significantly different.

Fornaini et al compared a blue-violet laser $(405 \mathrm{~nm})$ to a traditional halogen lamp and a LED deviceon two different resins, analyzing the conversion degree (DC\%) of the double bond, the volumetric shrinkage and the depth of the cure. The laser had the worst performance regarding all the parametersobserved, probably due to this wavelength not being properly absorbed by camphorquinone. ${ }^{43}$

Yun et al investigated the depth of composite resins cured with a $473 \mathrm{~nm}$ diode-pumped solid-state laser by comparing it to a quartz-tungsten-halogen and a light-emitting-diode (LED) on three different composite resins. ${ }^{44}$ The refractive index, DC, microhardness and number of photons transmitted through the specimens of different thicknesses were evaluated, and the $473 \mathrm{~nm}$ laser showed the same quality of polymerization as the other devices,even with an important lower light intensity.

Baek et al, by using the same device, evaluated the compressive and flexural properties, as well as the microhardness, using a compression test, the threepoint bending test and the Vickers test. They compared the laser device to a quartz-tungsten-halogen lamp and two LEDs and the results showed that the $473 \mathrm{~nm}$ laser is able to cure composite resins with mechanical properties comparable to those obtained using the other light-curing device, but with a much lower light intensity. ${ }^{45}$ 
A similar study by Jang et $\mathrm{al}^{46}$ showed the same results and on the nanocomposite resins as well. In a recent paper, Drost et $\mathrm{al}^{47}$ compared the effectiveness of photopolymerization in composite resins using the blue laser, LED and halogen bulb lamp, concluding that the $445 \mathrm{~nm}$ blue diode laser yieldscomparable results to the halogen lamp and LED in terms of curing depth and temperature elevation.

\section{Oral Surgery}

Fornaini et al in an ex vivo study ${ }^{48}$ performed on bovine tongue samples compared five differentlaser wavelengths used in dentistry and showed that a $450 \mathrm{~nm}$ diode laser obtained the bestperformance in terms of superficial and deep temperature control, coupled with the best quality of incision, evaluated by a pathologist. Brown et al., in a similar study comparing $450 \mathrm{~nm}$ and $970 \mathrm{~nm}$ diode lasers in 240 samples from porcine oral tissue, demonstrated a better efficiency and a lower thermal elevation with a blue diode laser by histological analysis. ${ }^{49}$

These results were confirmed with an in vivo study on 93 patients, performed by Gobbo et al who compared a $450 \mathrm{~nm}$ diode laser with a $970 \mathrm{~nm}$ diode laser and quantic molecular resonance surgery, and obtained minimal thermal damage, scant signs of inflammation, no bleeding and high compliancefrom patients..$^{50}$ Biasotto and Ottaviani demonstrated with several clinical cases that the use of thiswavelength in oral surgery represents a new and original approach in terms of efficiency and patientcomfort. ${ }^{51}$ Fornaini et al, in a case report, described the removal of a fibroma from the lip of a youngwoman with great success in terms of patient comfort and esthetic results. $^{52}$

Matys et al., in an in vivo study on 45 pig jaws, compared a blue diode laser $(450 \mathrm{~nm})$ to an infrareddiode laser (980 $\mathrm{nm}$ ) and analyzed the thermal elevation during implant uncovering. The results showed that the blue laser, when used in a non-contact mode, controls overheating well during irradiation. ${ }^{53}$

Reichelt et al, in a very interesting in vitro research on mono-layer cultures, obtained at two different lines and irradiated by two diode lasers (445 $\mathrm{nm}$ and $970 \mathrm{~nm}$ ), analyzed the healing speed, morphology, and thermal elevation of the samples and observed that the blue laser demonstrated a great capacity for coagulation, coupled with very low penetration in depth and minimal thermal sideeffects. ${ }^{54}$

\section{Periodontics}

The high antimicrobic effects of the blue laser, as previously described, may find a clinical applicationin periodontology for the decontamination of the gingival pockets, as well as a reduction ofinflammation, thanks to its biomodulating effects.

Bocher et al. compared different decontamination systems in an experimental model consisting of ninety-one bars of titanium, contaminated with an artificial biofilm formed by common pathogenic periodontal bacteria and put into an experimental model of periodontal pockets. ${ }^{55}$ The results showed that the antimicrobial photothermal therapy had the greatest antibacterial power and the association of curcumin and $445 \mathrm{~nm}$ laser irradiation did not improve the antibacterial effectiveness when compared to the laser alone.

\section{Endodontics}

The first utilization of a laser in endodontics, described by Weichman and Johnson in $1971,{ }^{56}$ reported the in vitro apical foramen sealing with a high-power carbon dioxide $\left(\mathrm{CO}_{2}\right)$ laser. Since then, a great number of in vitro studies focusing on the use of lasers in endodontics have been published, ${ }^{57}$ however, the clinical endodontic applications only began in the late 1990s with the development of new delivery systems, particularly optic fibers and thin endodontic tips. Today, lasers can be used in a great number of clinical situations such as pulp capping/ pulpotomy, cleaning and disinfecting and obturating the root canals, endodontic retreatment, and apical surgery. ${ }^{58}$

In an ex-vivo study on 140 human single-rooted teeth, Anić et al analyzed temperature, permeability and morphologic changes of the root canal walls irradiated by $\mathrm{CO}_{2}$, Nd:YAG and argon lasers; all

three laser devices demonstrated their capability to produce a glazed-like surface and, with significant differences between them, to induce an increase in permeability. ${ }^{59}$

\section{Orthodontics}

Recently, blue lasers have also started to be used in orthodontics.

Stein et al, in an ex vivo study on 18 humans extracted third molars, analyzed the thermal elevation during $450 \mathrm{~nm}$ diode laser irradiation during the debonding of ceramic brackets, demonstrating, by IR thermal camera and pulp circulation simulation, the absolute safety of this technique from the pulp vitality point of view. ${ }^{60}$ The same authors, in a different ex vivo study performed on 30 human extracted third molars, measured a decrease in the brackets adhesion to the enamel after blue laser irradiation, demonstrating the effectiveness of this technique in ceramic bracket removal, avoiding the risk of enamel fractures or damage. ${ }^{61}$

In 2020, Knaup et al, in an ex vivo study on 70 bovine teeth, evaluated the effect of the blue laseron the adhesion of metallic brackets before debonding, demonstrating that this technique does not significantly reduce their shear bond strength without influencing the volume of remaining adhesiveon the teeth surface ${ }^{62}$.

\section{Conclusion}

Blue and blue-violet diode lasers represent new and 
effective tools to be used in a large number of applications in the field of dentistry. Further studies will be necessary to clarify the potential of thesewavelengths.

\section{Ethical Considerations}

Not applicable.

\section{Conflict of Interests}

The authors declare no conflict of interest.

\section{References}

1. Frame JW, Morgan D, Rhys Evans PH. Tongue resection with the $\mathrm{CO} 2$ laser: the effects of past radiotherapy on postoperative complications. Br J Oral Maxillofac Surg. 1988 Dec;26(6):464-71. doi: 10.1016/0266-4356(88)900678.

2. Ortega-Concepción D, Cano-Durán JA, Peña-Cardelles JF, Paredes-Rodríguez VM, González- Serrano J, LópezQuiles J. The application of diode laser in the treatment of oral soft tissues lesions.A literature review. J Clin Exp Dent. 2017 Jul 1;9(7): 925-928. doi: 10.4317/jced.53795.

3. Fornaini C, Rocca JP. Oral Laserology. Italy: ED editor, Bologna; 2015.

4. Fornaini C, Rocca JP, Merigo E, Meleti M, Manfredi M, Nammour S, Vescovi P. Low energy KTP laser in oral soft tissue surgery: A 52 patients clinical study. Med Oral Patol Oral Cir Bucal. 2012;17:287-291. doi: 10.4317/ medoral.17428.

5. Kelsey WP, Blankenau RJ, Powell GL. Application of the argon laser to dentistry. Lasers Surg Med. 1991;11:495-498. doi: 10.1002/lsm.1900110602.

6. Fornaini C, Sozzi M, Merigo E, Pasotti P, Selleri S, Cucinotta AM. Supercontinuum source in the investigation of lasertissue interactions: "ex vivo" study. J. Biomed 2017; 2: 12-19. doi:10.7150/jbm.17059

7. Masson-Meyers DS, Bumah VV, Biener G, Raicu V, Enwemeka CS. The relative antimicrobial effect of blue 405 $\mathrm{nm}$ LED and blue $405 \mathrm{~nm}$ laser on methicillin-resistant Staphylococcus aureus in vitro. Lasers Med Sci. 2015 Dec;30(9):2265-71. doi: 10.1007/s10103-015-1799-1.

8. Enwemeka CS. Antimicrobial blue light: an emerging alternative to antibiotics. Photomed Laser Surg. 2013 Nov;31(11):509-11. doi: 10.1089/pho.2013.9871.

9. Biener G, Masson-Meyers DS, Bumah VV, Hussey G, Stoneman MR, Enwemeka CS, Raicu V. Blue/violet laser inactivates methicillin-resistant Staphylococcus aureus by altering its transmembrane potential. $J$ Photochem Photobiol B. 2017 May; 170:118-124. doi:10.1016/j. jphotobiol.2017.04.002.

10. de Sousa NT, Santos MF, Gomes RC, Brandino HE, Martinez R, de Jesus Guirro RR. Blue Laser Inhibits Bacterial Growth of Staphylococcus aureus, Escherichia coli, and Pseudomonas aeruginosa. Photomed Laser Surg. 2015 May;33(5):278-82. doi: 10.1089/pho.2014.3854.

11. Merigo E, Conti S, Ciociola T, Fornaini C, Polonelli L, Lagori G, Manfredi M, Vescovi P. Effect of different wavelengths and dyes on Candida albicans: In vivo study using Galleria mellonella as an experimental model. Photodiagnosis Photodyn Ther. 2017 Jun; 18:34-38. doi:10.1016/j. pdpdt.2017.01.181.
12. Merigo E, Conti S, Ciociola T, Manfredi M, Vescovi P, Fornaini C. Antimicrobial Photodynamic Therapy Protocols on Streptococcus mutans with Different Combinations of Wavelengths and Photosensitizing Dyes. Bioengineering (Basel). 2019 May 10;6(2). pii: E42. doi:10.3390/bioengineering6020042.

13. Merigo E, Chevalier M, Conti S, Ciociola T, Fornaini C, Manfredi M, Vescovi P, Doglio A: Antimicrobial effect on Candida albicans biofilm by application of different wavelengths and dyes and the synthetic killer decapeptide KP. Laser Therapy, 2019, Sep 30;28(3):180-186. doi:10.5978/ islsm.28_19-OR-14.

14. Azizi A, Shohrati P, Goudarzi M, Lawaf S, Rahimi A. Comparison of the Effect of Photodynamic Therapy with Curcumin and Methylene Blue on Streptococcus mutans Bacterial Colonies. Photodiagnosis Photodyn Ther. 2019 Jun 5. pii: S1572-1000(19)30158-9. doi:10.1016/j. pdpdt.2019.06.002.

15. Rupel K, Zupin L, Ottaviani G, Bertani I, Martinelli V, Porrelli D, Vodret S, Vuerich R, Passos da Silva D, Bussani R, Crovella S, Parsek M, Venturi V, Di Lenarda R, Biasotto M, Zacchigna S. Blue laser light inhibits biofilm formation in vitro and in vivo by inducing oxidative stress. NPJ Biofilms Microbiomes. 2019 Oct 9; 5:29. doi: 10.1038/ s41522-019-0102-9

16. Zupin L, Caracciolo I, Tricarico PM, Ottaviani G, D’Agaro P, Crovella S. Antiviral properties of blue laser in an in vitro model of HSV-1 infection. Microbiol Immunol. 2018 May 11. doi: 10.1111/1348-0421.12600. doi: 10.1089/ pho.2015.9848.

17. Anders JJ, Lanzafame RJ, Arany PR. Low-Level Light/Laser therapy versus Photobiomodulation Therapy. Photomed Laser Surg. 2015; 33:183-4.

18. Tunér J, Hode L. Laser therapy in dentistry and medicine. 1996. Prima books, Sweden.

19. Kushibiki T, Awazu K. Controlling osteogenesis and adipogenesis of mesenchymal stromal cellsby regulating a circadian clock protein with laser irradiation. Int J Med Sci. 2008; 5(6):319-26. doi: 10.7150/ijms.5.319.

20. Kushibiki T, Awazu K. Blue laser irradiation enhances extracellular calcification of primary mesenchymal stem cells. Photomed Laser Surg. 2009 Jun; 27(3):493-8. doi:10.1089/pho.2008.2343.

21. Kushibiki T, Hirasawa T, Okawa S, Ishihara M. Blue laser irradiation generates intracellular reactive oxygen species in various types of cells. Photomed Laser Surg. 2013 Mar;31(3):95-104. doi:10.1089/pho.2012.3361.

22. Mikami R, Mizutani K, Aoki A, Tamura Y, Aoki K, Izumi Y. Low-level ultrahigh-frequency and ultrashort-pulse blue laser irradiation enhances osteoblast extracellular calcification by upregulating proliferation and differentiation via transient receptor potential vanilloid 1 . Lasers Surg Med. 2018 Apr; 50(4):340-352. doi: 10.1002/ lsm. 22775 .

23. Fisher G. The bleaching of discolored teeth with $\mathrm{H}_{2} \mathrm{O}_{2}$. Dent. Cosmos. 1911; 53:246-247.

24. Fornaini C, Lagori G, Merigo E, Meleti M, Manfredi M, Guidotti R, Serraj A, Vescovi P. Analysis of shade, temperature and hydrogen peroxide concentration during dental bleaching: in vitro study with the KTP and diode 
lasers. Lasers Med Sci. 2013 Jan; 28(1):1-6. doi:10.1007/ s10103-011-1037-4.

25. Cassoni A, Rodrigues JA. Argon laser: a light source alternative for photopolymerization and in- office tooth bleaching. Gen Dent. 2007 Sep-Oct; 55(5):416-9. Review.

26. Tano E, Otsuki M, Kato J, Sadr A, Ikeda M, Tagami J. Effects of $405 \mathrm{~nm}$ diode laser on titaniumoxide bleaching activation. Photomed Laser Surg. 2012 Nov;30(11):648-54. doi: 10.1089/pho.2012.3273. doi: 10.1089/pho.2012.3273

27. Meniga A, Tarle Z, Ristic M, Sutalo J, Pichler G. Pulsed blue laser curing of hybrid composite resins. Biomaterials. 1997 Oct;18(20):1349-54.

28. Benedicenti A, Guainazzo G, Gherlone EF, Martino AR, Guarneri L, Rinaldi F. Use of light emitted from an argon laser for the polymerization of composites usually polymerized by UV or halogen light. Immediate advantages and long-term clinical aspects. Parodontol Stomatol (Nuova). 1984 Sep-Dec;23(3):105-7.

29. Benedicenti A, Daneo M, Verrando M, Guarneri L, Martino AR, Gherlone EF. Evaluation of water absorption by a composite, Durafill, polymerized with argon laser light, in relation to normal polymerization. Parodontol Stomatol (Nuova). 1984 Sep-Dec;23(3):27-9.

30. Benedicenti A, Daneo M, Verrando M, Guarneri L, Martino AR, Gherlone EF. Evaluation of thehardness of a composite, Durafill, polymerized with argon laser light, in relation to normal polymerization. Parodontol Stomatol (Nuova). 1984 Sep-Dec; 23(3):39-42.

31. Benedicenti A, Daneo M, Verrando M, Guarneri L, Martino AR, Gherlone EF. Evaluation of the wear of a composite, Durafill, polymerized with argon laser light, in relation to normal polymerization. Parodontol Stomatol (Nuova). 1984 Sep-Dec;23(3):51-3.

32. Benedicenti A, Verrando M, Daneo M, Sommazzi N, Coriandolo D, Zanelli F. Experimental protocol for the application of laser light for the polymerization of composites--controlled with $904 \mathrm{~nm}$. laser light-inducted with argon laserlight (isocentric polymerization). Parodontol Stomatol (Nuova). 1984 Sep-Dec;23(3):63-8.

33. Séverin C. The effect of argon laser radiation on the polymerization of photocomposites: bondingof orthodontic brackets. J Biomater Dent. 1985 Apr;1(2):111-2, 161-5.

34. Kelsey WP 3rd, Blankenau RJ, Powell GL, Barkmeier WW, Cavel WT, Whisenant BK. Enhancement of physical properties of resin restorative materials by laser polymerization. Lasers Surg Med. 1989;9(6):623-7. doi: 10.1002/lsm.1900090613

35. Powell GL, Kelsey WP, Blankenau RJ, Barkmeier WW. The use of an argon laser forpolymerization of composite resin. J Esthet Dent. 1989 Jan;1(1):34-7. doi: 10.1111/j.17088240.1989.tb01035.x.

36. Blankenau RJ, Powell GL, Kelsey WP, Barkmeier WW. Post polymerization strength values ofan argon laser cured resin. Lasers Surg Med. 1991;11(5):471-4. doi: 10.1002/ lsm. 1900110513.

37. Blankenau RJ, Kelsey WP, Powell GL, Shearer GO, Barkmeier WW, Cavel WT. Degree of composite resin polymerization with visible light and argon laser. Am J Dent. 1991 Feb; 4(1):40-2.

38. Kelsey WP, Blankenau RJ, Powell GL, Barkmeier WW,
Stormberg EF. Power and timerequirements for use of the argon laser to polymerize composite resins. J Clin Laser Med Surg. 1992Aug;10(4):273-8. doi: 10.1089/clm.1992.10.273

39. Calura G, Nonato M, Franchi M, Pagnanelli M. Effect of laser light on polymerization of composite materials]. Minerva Stomatol. 1989 Apr; 38(4):395-403.

40. Shanthala BM, Munshi AK. Laser vs visible-light cured composite resin: an in vitro shear bond study. J Clin Pediatr Dent. 1995 Winter;19 (2):121-5.

41. Fleming MG, Maillet WA. Photopolymerization of composite resin using the argon laser. J Can Dent Assoc. 1999 Sep;65(8):447-50. Review.

42. Pahlevan A, Tabatabaei MH, Arami S, Valizadeh S. Effect of LED and Argon Laser on Degree of Conversion and Temperature Rise of Hybrid and Low Shrinkage Composite Resins. Open Dent J. 2016 Sep 30; 10:538-545. doi: $10.2174 / 1874210601610010538$

43. Fornaini C, Lagori G, Merigo E, Rocca JP, Chiusano M, Cucinotta A. $405 \mathrm{~nm}$ diode laser, halogen lamp and LED device comparison in dental composites cure: an "in vitro" experimental trial. Laser Ther. 2015 Dec 30; 24(4):265-74. doi: 10.5978/islsm.15-OR-16.

44. Yun DI, Ku RM, Son SA, Park JK, Ko CC, Kim HI, Kwon YH. Influence of a blue DPSS laser on specimen thickness of composite resins. Photomed Laser Surg. 2012 Sep;30(9):536-42. doi: 10.1089/pho.2012.3231.

45. Baek DM, Park JK, Son SA, Ko CC, Garcia-Godoy F, Kim HI, Kwon YH. Mechanical properties of composite resins light-cured using a blue DPSS laser. Lasers Med Sci. 2013 Feb;28(2):597-604. doi: 10.1007/s10103-012-1117-0.

46. Jang CM, Seol HJ, Kim HI, Kwon YH. Effect of different blue light-curing systems on the polymerization of nanocomposite resins. Photomed Laser Surg. 2009 Dec;27(6):871-6. doi: 10.1089/pho.2008.2322.

47. Drost T, Reimann S, Frentzen M, Meister J. Effectiveness of photopolymerization in composite resins using a novel 445-nm diode laser in comparison to LED and halogen bulb technology. LasersMed Sci. 2019 Jun; 34(4):729-736. doi: 10.1007/s10103-018-2651-1.

48. Fornaini C, Merigo E, Rocca JP, Lagori G, Raybaud H, Selleri S, Cucinotta A: $450 \mathrm{~nm}$ Blue Laser and Oral Surgery: Preliminary ex vivo Study. J Contemp Dent Pract. 2016 Oct 1;17(10):795- 800. doi: 10.5005/jp-journals-10024-1933

49. Braun A, Kettner M, Berthold M, Wenzler JS, Heymann PGB, Frankenberger R. Efficiency of soft tissue incision with a novel 445-nm semiconductor laser. Lasers Med Sci. 2018 Jan;33(1):27-33.doi: 10.1007/s10103-017-2320-9.

50. Gobbo M, Bussani R, Perinetti G, Rupel K, Bevilaqua L, Ottaviani G, Biasotto M: Blue diode laser versus traditional infrared diode laser and quantic molecular resonance scalpel: clinical and histological findings after excisional biopsy of benign oral lesions. J. Biomed. Opt. 22(12), 121602 (2017), doi: 10.1117/1.JBO.22.12.121602

51. Biasotto M, Ottaviani G: Le lunghezze d'onda in chirurgia: l'impiego del laser blu. Dental Cadmos 2018; 86(5)

52. Fornaini C, Rocca JP, Merigo E. $450 \mathrm{~nm}$ diode laser: A new help in oral surgery. World J Clin Cases. 2016 Sep 16;4(9):253-7. doi: 10.12998/wjcc.v4.i9.253.

53. Matys J, Flieger R, Dominiak M. Effect of diode lasers with wavelength of 445 and $980 \mathrm{~nm}$ on atemperature rise when 
uncovering implants for second stage surgery: An ex-vivo study in pigs. Adv Clin Exp Med. 2017 Jul; 26(4):687-693. doi: $10.17219 /$ acem/68943.

54. Reichelt J, Winter J, Meister J, Frentzen M, Kraus D. A novel blue light laser system for surgicalapplications in dentistry: evaluation of specific laser-tissue interactions in monolayer cultures. Clin Oral Investig. 2017 May; 21(4):985-994. doi: 10.1007/s00784-016-1864-6.

55. Böcher S, Wenzler JS, Falk W, Braun A. Comparison of different laser-based photochemical systems for periodontal treatment. Photodiagnosis Photodyn Ther. 2019 Sep; 27:433-439. doi: 10.1016/j.pdpdt.2019.06.009.

56. Weichman JA, Johnson EM. Laser use in endodontics. A preliminary investigation. Oral Surg Oral Med Oral Pathol. 1971. Mar;31(3):416-20. doi:10.1016/00304220(71)90164-2

57. Kimura Y, Wilder-Smith P, Matsumoto K. Lasers in endodontics: a review. Int Endod J. 2000. May;33(3):17385. doi:10.1046/j.1365-2591.2000.00280.x 31.

58. Stabholz A, Zeltser R, Sela M, Peretz B, Moshonov J, Ziskind D, et al. The use of lasers in dentistry: principles of operation and clinical applications. Compend Contin Educ Dent. 2003. Dec; 24(12):935-48
59. Anić I, Tachibana H, Masumoto K, Qi P. Permeability, morphologic and temperature changes of canal dentine walls induced by Nd: YAG, CO2 and argon lasers. Int Endod J. 1996 Jan;29(1):13-22. doi: 10.1111/j.1365-2591.1996. tb01354.x.

60. Stein S, Wenzler J, Hellak A, Schauseil M, KorbmacherSteiner H, Braun A. Intrapulpal Temperature Increases Caused by $445-\mathrm{nm}$ Diode Laser-Assisted Debonding of Self-Ligating Ceramic Brackets During Simulated Pulpal Fluid Circulation. Photomed Laser Surg. 2018 Apr;36(4):185-190. doi: 10.1089/pho.2017.4356.

61. Stein S, Hellak A, Schauseil M, Korbmacher-Steiner H, Braun A. Effects of 445-nm Diode Laser- Assisted Debonding of Self-Ligating Ceramic Brackets on Shear Bond Strength. Photomed Laser Surg. 2018 Jan;36(1):31-36. doi:36

62. Knaup T, Korbmacher-Steiner H, Braun A, Wenzler JS, Knaup I, Stein S. Effects of 445-nm Diode Laser-Assisted Debonding of Metallic Brackets on Shear Bond Strength and Enamel Surface Morphology. Photobiomodul Photomed Laser Surg. 2020 Mar;38(3):160-166. doi: 10.1089/photob.2019.4704. 